\title{
The Gender of COVID-19 Experts in Newspaper Articles: a Descriptive Cross-Sectional Study
}

\author{
Sarah Fletcher ${ }^{7}$, Moss Bruton Joe, BHSC ${ }^{2}$, Santanna Hernandez, BSW², \\ Inka Toman, MD MSc ${ }^{3}$, Tyrone G. Harrison, MD ${ }^{4,5}$, and Shannon M. Ruzycki, MD MPH ${ }^{4,5}$ (i)
}

${ }^{1}$ Faculty of Medicine, University of British Columbia, Vancouver, British Columbia, Canada; ${ }^{2}$ Cumming School of Medicine, University of Calgary, Calgary, Alberta, Canada; ${ }^{3}$ Department of Medicine, Faculty of Medicine \& Dentistry, University of Alberta, Edmonton, Alberta, Canada;

${ }^{4}$ Department of Medicine, Cumming School of Medicine, University of Calgary, Calgary, Alberta, Canada; ${ }^{5}$ Department of Community Health Sciences, Cumming School of Medicine, University of Calgary, Calgary, Alberta, Canada.

BACKGROUND: Pre-existing gender-based disparities in academia may have worsened during the COVID-19 pandemic. Being cited as an expert source in newspaper articles about COVID-19 may increase an individual's research or leadership profile. In addition, visibility in a newspaper article is an important component of representation in academia.

OBJECTIVE: To determine whether women were underrepresented as COVID-19 expert sources in print newspapers in the USA.

DESIGN: We undertook a cross-sectional study of English-language newspaper articles that addressed the COVID-19 pandemic and that were published in the top 10 most widely read newspapers in the USA between April 1 and April 15, 2020.

MAIN MEASURES: We extracted the names of all people cited as expert sources and categorized the gender of each expert source based on pronoun usage within the article or on a business, university, or organization website. The professional role of each expert was assigned based on their description in the article.

KEY RESULTS: Of 2297 expert sources identified, $35.9 \%$ (95\% confidence interval [CI] 33.9-37.8\%; $n=$ $824)$ were women and $63.7 \%$ were men (95\% CI 61.8 $65.7 \% ; n=1464)$. This result was similar when considering unique experts in each newspaper and for all included newspapers; of the 1738 unique experts per newspaper, 34.6\% were women (95\% CI 32.3-36.8\%; $n$ $=601$ ), and of the 1593 unique experts in all newspapers, $36.5 \%$ were women (95\% CI 34.1-38.9\%; $n=$ 581). Of articles with multiple experts referenced ( $n=$ 374), 102 cited only men experts (27.3\%) and 44 cited only women experts (11.8\%). Women were underrepresented as experts as Healthcare Workers and Professionals, Non-STEM Experts, Public Health Leaders, and STEM Scientists. There were no differences in the proportion of women experts between newspapers or between different regions of the USA.

Supplementary Information The online version contains supplementa ry material available at https://doi.org/10.1007/s11606-020-06579-3.

Received September 8, 2020

Accepted December 29, 2020

Published online January 19, 2021
CONCLUSIONS: Altogether, our findings support that men academics outnumber women as COVID-19 experts in newspaper articles.

KEY WORDS: gender-based disparities; COVID-19 pandemic; expertise.

J Gen Intern Med 36(4):1011-16

DOI: $10.1007 / \mathrm{s} 11606-020-06579-3$

(c) Society of General Internal Medicine 2021

\section{INTRODUCTION}

The COVID-19 pandemic has shed further light on preexisting disparities that disadvantage women academics in representation, publication, research opportunities, and caregiving responsibilities. Anecdotal reports of the impact of increased barriers for women academics due to COVID-19 1 have been supported by evidence of a decrease in publications for women academics since the pandemic began. ${ }^{2,3}$ Furthermore, women are underrepresented in pandemic decisionmaking and leadership roles. ${ }^{4}$ Altogether, this growing evidence highlights that women academics are being excluded from key opportunities during the COVID-19 pandemic. The impact of these exclusions on the career trajectories for women academics is not yet known and may not be realized for years to come.

Previous evidence suggests that only one woman scientist is quoted for every five men scientists in British news media. ${ }^{5}$ This is similar to proportions of women scientists found in Canadian newspapers, where only $23.8 \%$ of experts cited were women. ${ }^{6}$ Lack of visibility of women science experts in news media suggests that there are fewer opportunities for academic women and also contributes to a culture where women are less likely to see themselves represented as experts. In this crosssectional study, we aimed to document and compare the representation of women experts versus men experts in newspaper coverage of the COVID-19 pandemic in the United States (US). With the evidence of disparities between women and men already being documented in other academic domains, we hypothesized that we would find higher proportions of men experts in newspaper coverage compared with women. 


\section{METHODS}

This descriptive cross-sectional study examined the proportion of women, men, and non-binary gender experts quoted in major American newspapers in publicly available articles referring to the SARS-CoV-2 pandemic. Institutional ethics board approval was not applicable given the study design. This manuscript is reported according to the Strengthening the Reporting of Observational Studies in Epidemiology (STROBE) guidelines ${ }^{7}$ and the Preferred Reporting Items for Systematic Reviews and Meta-Analyses (PRISMA) guidelines when describing the systematic search strategy used to identify articles.

Factiva and the US Major Dailies databases were used to identify newspaper articles for inclusion. The full search strategy for each database was developed after consultation with a librarian and is available in Appendix 1 and 2. Newspaper articles were eligible if they were published between April 1, 2020, and April 15, 2020, in the English language, containing the words "COVID-19" or "coronavirus," and were found in the print version of one of the top 10 most widely read newspapers in the USA (USA Today, Wall Street Journal, New York Times, New York Post, Los Angeles Times, Washington Post, Star Tribune [Minneapolis-St Paul], Newsday, Chicago Tribune, and the Boston Globe). ${ }^{8}$ Online-only content, letters to the editor, advice columns, article corrections, and obituaries were excluded. Articles published in duplicate in multiple newspapers were included only once in the primary newspaper.

Each newspaper article was reviewed by one study team member to identify eligible expert sources. Reviewers used a standardized data extraction form that was pilot tested by all members of the study team (Appendix 3). Twenty randomly selected articles were reviewed by two study members to determine Cohen's kappa of data extraction. The date of publication, article title, reporter(s), expert name, expert gender as determined by pronouns used within the article, expert gender as identified by another source, and expert title or position were extracted. Furthermore, members of our research team contacted each newspaper editor a minimum of two times to determine if the newspaper had a policy on inclusion or gender related to expert sources.

All people mentioned in the text of the article were considered for inclusion as an expert source. To be included in our analysis, an expert source (1) had to be cited as an expert on health, health systems, or disease; (2) had to speak about SARS-CoV-2, COVID-19, or coronavirus disease; and (3) had to speak about human impacts or human disease (Table 1). People were not included as an expert if they were mentioned only to recount or describe events rather than provide information as an expert. In addition, people were not included as an expert if they were referenced only as a spokesperson for an agency or organization. We excluded anonymous and unnamed sources. When a reviewer was unsure whether to include a potential expert, another member
Table 1 Identification of Expert Sources in Newspaper Articles

\begin{tabular}{|c|c|c|}
\hline$\overline{\text { Question }}$ & $\begin{array}{l}\text { Example of an } \\
\text { excluded person }\end{array}$ & $\begin{array}{l}\text { Example of an } \\
\text { included expert }\end{array}$ \\
\hline $\begin{array}{l}\text { Is the person } \\
\text { included as an } \\
\text { expert on health, } \\
\text { health systems, or } \\
\text { disease? }\end{array}$ & $\begin{array}{l}\text { A governor giving a } \\
\text { daily update on case } \\
\text { numbers. }\end{array}$ & $\begin{array}{l}\text { A public health } \\
\text { official giving a daily } \\
\text { update on COVID-19 } \\
\text { in the community. }\end{array}$ \\
\hline $\begin{array}{l}\text { Is the person being } \\
\text { mentioned as part } \\
\text { of storytelling only, } \\
\text { to recount events? }\end{array}$ & $\begin{array}{l}\text { An article about an } \\
\text { actor impersonating } \\
\text { Dr. Anthony Fauci. }\end{array}$ & $\begin{array}{l}\text { Dr. Anthony Fauci } \\
\text { discussing the risks } \\
\text { and benefits of } \\
\text { wearing a facial } \\
\text { covering in public. }\end{array}$ \\
\hline \multirow[t]{2}{*}{$\begin{array}{l}\text { Is the person } \\
\text { speaking about } \\
\text { COVID-19 disease } \\
\text { or the coronavirus? }\end{array}$} & $\begin{array}{l}\text { A physician } \\
\text { discussing heart } \\
\text { disease. }\end{array}$ & $\begin{array}{l}\text { A physician } \\
\text { describing heart } \\
\text { disease in patients } \\
\text { with COVID-19. }\end{array}$ \\
\hline & $\begin{array}{l}\text { An epidemiologist } \\
\text { discussing the Ebola } \\
\text { pandemic. }\end{array}$ & $\begin{array}{l}\text { An epidemiologist } \\
\text { discussing the } \\
\text { COVID-19 pandemic. }\end{array}$ \\
\hline $\begin{array}{l}\text { Is the person } \\
\text { speaking about } \\
\text { human impacts or } \\
\text { human disease? }\end{array}$ & $\begin{array}{l}\text { A veterinarian } \\
\text { discussing the health } \\
\text { impact of coronavirus } \\
\text { in tigers. }\end{array}$ & $\begin{array}{l}\text { A veterinarian } \\
\text { discussing zoonotic } \\
\text { disease transmission } \\
\text { to humans. }\end{array}$ \\
\hline
\end{tabular}

of the study team also reviewed the article and both reviewers had to agree to include the expert.

Expert gender was assigned based on pronoun usage within the text article (he/him corresponded to a man expert, she/her corresponded to a woman expert, and other pronouns such as they/them or ze corresponded to a non-binary gender expert). If the expert's pronouns were not available in the article text, the expert's name and title were used to search the internet for a university, hospital, or business website to determine the expert's gender. If an expert was mentioned in another newspaper article, the pronouns from that article could be used to assign gender. An expert's gender was categorized as unknown if there were no pronouns or gender listed within the newspaper article or on an official university, hospital, or business website for the expert. An expert was included for each article that they were cited in, but an expert was included only once per newspaper article, even if cited multiple times within the article.

An expert's professional role was assigned to one of seven categories (healthcare worker/professional, health systems leader, miscellaneous, non-STEM expert, public health leader, physician, or STEM scientist) based on how their role was described in the newspaper text. Experts who had two or more roles described within the text were assigned based on the most advanced degree or role (e.g., Dr. Anthony Fauci was classified as a public health leader rather than as a physician) according to Rajan et al. ${ }^{4}$ Some newspapers emphasized different professional roles for the same expert; these experts were included in duplicate categories (e.g., Dr. Ashish Jha was classified as a STEM scientist when referred to as a professor in the Boston Globe and as a public health leader when referred to as the Director of the Harvard Global Health Institute in the New York Times).

We report proportion of women, men, or another gender experts in three separate analyses: the total number of experts, 
the number of unique experts in each individual newspaper ("per newspaper" analysis), and the number of unique experts in all included newspapers ("overall newspaper" analysis). Individual experts were only counted once per newspaper in the unique expert per newspaper analysis, even if they appeared in multiple articles in that newspaper (e.g., Dr. Deborah Birx was counted once for each newspaper) and once in the overall newspaper analysis (e.g., Dr. Birx was counted only once). Logistic regression estimates were transformed into estimates of the proportion of women experts and compared between individual newspapers and geographic regions of the USA (based on regions from the US Bureau of the Census). ${ }^{9}$ We did not compare the proportion of men and women experts statistically because there was no established baseline of potential men and women experts.

\section{RESULTS}

One newspaper was not accessible through database searching and was excluded from the analysis (Newsday). We therefore analyzed 4463 newspaper articles from nine newspapers. Of these, 3681 were included in our analysis and 969 articles included at least one expert source. Cohen's kappa demonstrated moderate agreement for expert source inclusion $(n=$ 54; 0.59 ; $95 \%$ CI $0.33-0.86$ ) and perfect agreement for assignment of gender $(n=41 ; 1.00 ; 95 \%$ CI $1.00-1.00)$. Only one newspaper (the Chicago Tribune) responded to inquiries about an inclusion policy for expert sources and that newspaper did not have such a policy.

In total, 2297 experts were referenced, of which $35.9 \%$ (95\% CI 33.9-37.8\%; $n=824$ ) were women, $63.7 \%$ were men $(95 \%$ CI $61.8-65.7 \% ; n=1464)$, and for $0.4 \%$, gender could not be assigned $(n=9)$ (Table 2$)$. There were no experts cited who used gender-neutral or alternative pronouns. The proportion of women experts was greater than $50 \%$ of all experts for only one newspaper, the Star Tribune (52.0\%; 95\% CI 42.1-61.9\%, range 32.4-52.0\%).

Considering only unique experts mentioned per newspaper, 1738 individuals were referenced, of which $34.6 \%$ were women $(95 \%$ CI $32.3-36.8 \% ; n=601), 64.9 \%$ were men $(95 \%$ CI $62.7-67.1 \% ; n=1128)$, and $0.05 \%$ whose gender was unknown $(n=9)$. After combining all experts from all included newspapers and removing duplicates, there were 1593 unique experts, of which $36.5 \%$ were women (95\% CI $34.1-38.9 \%$; $n$ $=581)$ and $63.2 \%$ were men (95\% CI $60.7-65.5 \%, n=1006)$, and 6 were unknown gender. Of articles with two or more experts cited $(n=374), 102$ cited only men experts $(27.3 \%)$ and 44 cited only women experts (11.8\%).

When analyzed by professional role, women were underrepresented as experts as Healthcare Workers and Professionals, Non-STEM Experts, Public Health Leaders, and STEM Scientists (Table 3). The proportion of women experts was similar to the presumed available pool of experts for Health Services Leaders and Physicians. There were no statistically significant differences in the proportion of women experts between different regions of the USA (Table 4) though there were differences between individual newspapers (Appendix 4).

\section{DISCUSSION}

In this cross-sectional descriptive study of the proportion of COVID-19 experts cited in top American newspapers, we report that men experts outnumbered women experts by almost twofold. This relationship persisted whether we examined all experts mentioned, only unique experts within a single newspaper, or only unique experts in all newspapers included. These findings support anecdotal reports that women academics have been underrepresented in newspaper coverage and evidence-based data demonstrating the exclusion of women from academic publication and leadership during the COVID19 pandemic. $^{1-4}$

The proportion of women experts cited in newspaper articles about the COVID-19 pandemic is greater than previous studies of the representation of women in news media. In a 2008 study of UK newspapers, only $16 \%$ of all quoted scientists were female. ${ }^{5}$ Similarly, a 2015 study of Canadian newspapers found that $23.8 \%$ of quoted experts were female. ${ }^{6}$ This may be because there are more women experts in fields related to COVID-19; for example, women comprise $41.1 \%$ of infectious disease physicians ${ }^{10}$ and $73 \%$ of public health degree recipients in the USA. ${ }^{11}$ Despite there being a significant proportion of women in these COVID-19 related professions, women account for only $13 \%$ of health systems $\mathrm{CEOs}^{12}$ and for two of the eighteen former administrators of the Centers for Disease Control and Prevention. ${ }^{13}$ This suggests that a lack of women in high-profile positions may also contribute to low representation of women experts in newspaper articles. Our analysis is not able to differentiate between gender bias in the selection of experts by reporters and the overall underrepresentation of women in senior leadership or medical roles.

Our findings are limited in several ways. We were unable to reliably categorize the field of expertise for newspaper sources due to variability in how the titles of experts were reported in each article as well as redundancy of categories for each expert (e.g., physicians who had public health degrees and held health systems leadership roles). For this reason, we cannot determine if the proportion of women experts is due to bias in the selection of newspaper sources, differential availability of women experts to participate in newspaper interviews, or a paucity of women with relevant expertise. ${ }^{14}$ As a result of not reliably knowing the overall gender composition of COVID-19 experts in the USA and elsewhere, we were unable to statistically compare the proportions of men versus women in the articles that were examined. Equality of representation at an arbitrary $50 \%$ threshold may not be appropriate if the total proportion of women that are COVID-19 experts is significantly different, and this additionally does not address equity concerns in 


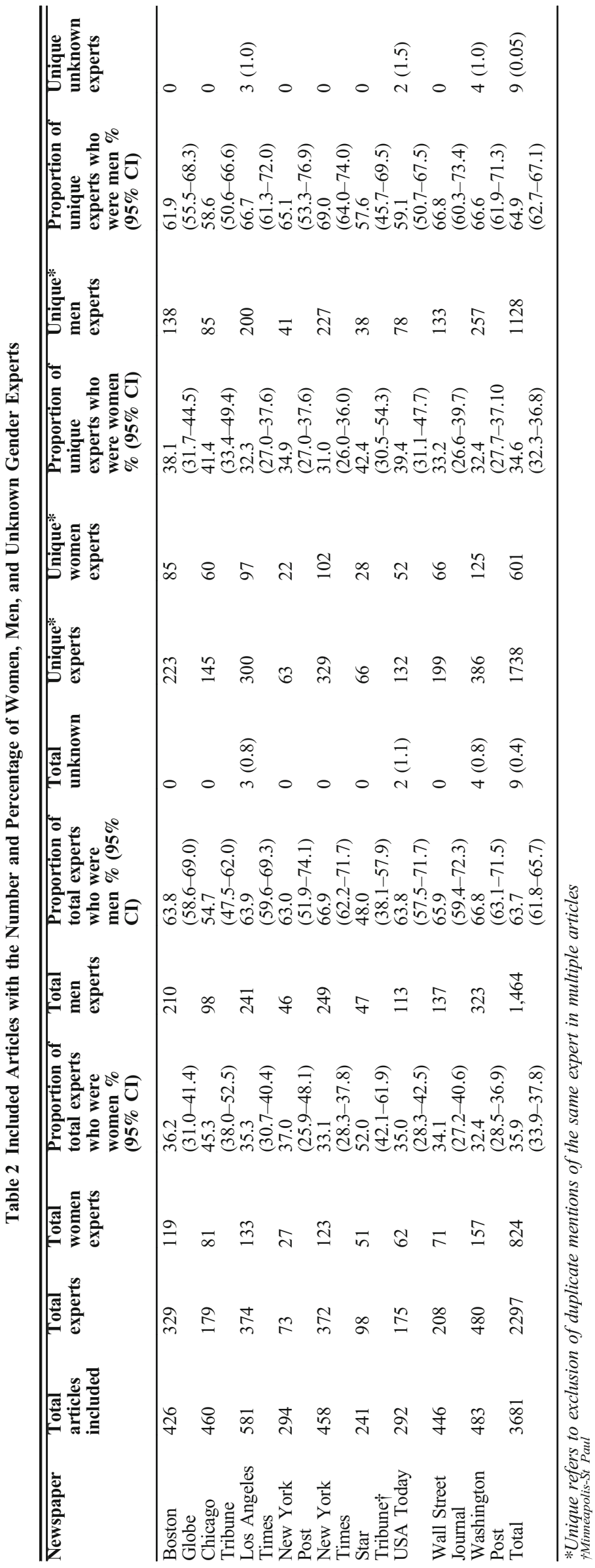


Table 3 Professional Role of Women Expert Sources for Included Newspaper Articles about COVID-19 Compared to Estimated Proportion of Women Experts by Professional Role in the USA

\begin{tabular}{llll}
\hline \hline $\begin{array}{l}\text { Expert } \\
\text { professional } \\
\text { role* }\end{array}$ & $\begin{array}{l}\text { Total } \\
\text { experts, } n \\
\text { (\% total) }\end{array}$ & $\begin{array}{l}\text { Total women } \\
\text { experts, } \boldsymbol{n} \text { (\% } \\
\text { of profession) }\end{array}$ & $\begin{array}{l}\text { Estimated } \\
\text { proportion of } \\
\text { women experts } \\
\text { in the profession } \\
\text { in the USA (\%) }\end{array}$ \\
\hline
\end{tabular}

\begin{tabular}{llll}
\hline Healthcare & 138 & $88(63.4)$ & $85 \%{ }^{17}$
\end{tabular}

Workers and

Healthcare

Professionals

Health Services $\quad 543 \quad 175(32.2)$

Leader

$32.4 \%$ of hospital executives $^{18}$ $52 \%$ of leaders of state Department of Health $52 \%$ of state Chief Health Officers

\begin{tabular}{|c|c|c|c|}
\hline $\begin{array}{l}\text { Non-STEM } \\
\text { Experts }\end{array}$ & 42 & $11(26.2)$ & $46 \%-77 \%^{19}$ \\
\hline $\begin{array}{l}\text { Experts } \\
\text { Miscellaneous }\end{array}$ & & & \\
\hline $\begin{array}{l}\text { Miscellaneous } \\
\text { Physician }\end{array}$ & 14 & $5(35,7)$ & \\
\hline Physician & 507 & $163(32.1)$ & $35.2 \%^{10}$ \\
\hline $\begin{array}{l}\text { Public Health } \\
\text { Leader }\end{array}$ & 391 & 139 (35.5) & $\begin{array}{l}70 \%{ }^{11} \text { of all } \\
\text { advanced degree } \\
\text { recipients }\end{array}$ \\
\hline STEM Scientists & 348 & $133(38.2)$ & $50 \%$ \\
\hline Total & 1971 & $708(35.9)$ & - \\
\hline
\end{tabular}

*Health Care Workers and Healthcare Professionals include any nonphysician employed in human healthcare work; Health Services Leader include anyone whose role was in administration of a hospital, longterm care facility, or other institution or in a political role; Non-STEM experts included any expert not in a Science, Technology, Engineering or Math field, such as sociology or psychology

representation. Furthermore, our results only capture print media and do not measure representation in other media such as television or academic editorials. Data collection occurred over a relatively short time period early in the pandemic, and though it is unlikely that newspaper expert identification practices have changed in a period of months, our results may not generalize to future time periods of the pandemic. In addition, we were

Table 4 Association of Publication Region with Proportion of Women Experts in COVID-19-Related Newspaper Articles

\begin{tabular}{lllll}
\hline \hline Region* & $\begin{array}{l}\text { Unique } \\
\text { experts } \\
\text { (number) } \dagger\end{array}$ & $\begin{array}{l}\text { Unique women } \\
\text { experts, } \boldsymbol{n}(\% \\
\text { of region } \\
\text { unique } \\
\text { experts) }\end{array}$ & $\begin{array}{l}\text { Odds ratio } \\
\mathbf{( 9 5 \%} \text { CI) }\end{array}$ & $\begin{array}{l}\boldsymbol{p} \\
\text { value }\end{array}$ \\
\hline Northeast & 814 & $275(33.8)$ & $\begin{array}{l}\text { Reference } \\
\text { Group }\end{array}$ & - \\
Midwest & 211 & $88(41.7)$ & $\begin{array}{l}1.30(0.96- \\
1.77)\end{array}$ & 0.09 \\
West & 300 & $97(32.3)$ & $\begin{array}{l}1.91(0.69- \\
1.21)\end{array}$ & 0.69 \\
South & 518 & $177(34.2)$ & $\begin{array}{l}0.99(0.79- \\
1.25)\end{array}$ & 0.79 \\
& & & & \\
\hline
\end{tabular}

*Regions are defined by the US Bureau of the Census: ${ }^{9}$ Northeast includes the Boston Globe, New York Post, New York Times, and Wall Street Journal; Midwest includes the Chicago Tribune and Star Tribune; West includes the Los Angeles Times; South includes the Washington Post and USA Today

tThe total number of unique experts includes unique counted per region and the total number is therefore greater than shown in Table 2 unable to capture data on how other axes of discrimination, such as race, ethnicity, Indigenous status, or ability, may have intersected to impact representation as COVID-19 experts. These data are critical to documenting the full scope of bias in academia.

Documentation of the types of disparities encountered by women in academia is important to recognize the lived experiences of discrimination and to develop interventions to address these disparities. For example, men academics may consider declining opportunities and recommending their women colleagues as an act of allyship. Academic leadership should consider how high-profile media opportunities should be counted in promotion and advancement decisions, given this evidence of potential bias that disadvantages women. The responsibility to ensure equitable representation is shared by media organizations as well. Despite recognizing this as an important issue in publishing, ${ }^{14}$ only one newspaper editor responded to our requests for information on equity policies for referenced experts (which they did not have). There is conflicting literature on whether the gender of the reporter is associated with greater representation of women sources. ${ }^{5,6}$ Development of such policies may provide women and non-binary people with opportunities that have primarily been given to men. Lastly, there are examples of online, topic-specific bibliographies of the contact information or research works of experts from underrepresented groups that can be used to replace the networks of connections that tend to favor the in-group. ${ }^{15,16}$ Academic departments could consider creating similar repositories for journalists to highlight underrepresented experts.

\section{CONCLUSION}

Overall, this study documents that men academics outnumber women academics in COVID-19 newspaper reporting and adds to the growing body of evidence demonstrating how the pandemic has affected the careers of men and women academics.

Acknowledgments: The authors acknowledge Zahra Premji, for her assistance in developing the search strategy.

Corresponding Author: Shannon M. Ruzycki, MD MPH; Department of Community Health Sciences, Cumming School of Medicine, University of Calgary, Calgary, Alberta, Canada

Author Contribution All authors contributed to data collection, editing of the manuscript, and read and approve the final manuscript. S.M.R. and I.T. conceived the project. S.M.R. and T.G.H. contributed to data analysis. S.M.R. wrote the first draft of the manuscript.

Data Availability Project data are available from the corresponding author upon reasonable request.

\section{Compliance with Ethical Standards:}

This project did not require ethics application due to the study design and public nature of the data. Consent was not required for participation due to the public nature of the data. 
Conflict of Interest: The authors declare that they do not have a conflict of interest.

\section{REFERENCES}

1. Carr T. Coronavirus coverage and the silencing of female expertise. Undark; 2020 June 222020.

2. Andersen JP, Nielsen MW, Simone NL, Lewiss RE, Jagsi R. MetaResearch: COVID-19 medical papers have fewer women first authors than expected. eLife. 2020;9:e58807.

3. Gabster BP, van Daalen K, Dhatt R, Barry M. Challenges for the female academic during the COVID-19 pandemic. Lancet. 2020

4. Rajan D, Koch K, Rohrer K, Bajnoczki C, Socha A, Voss M, et al. Governance of the Covid-19 response: a call for more inclusive and transparent decision-making. BMJ Glob Health. 2020;5(5).

5. Kitzinger J, Chimba M, Williams A, Haran J, Boyce T. Gender, Stereotypes and Expertise in the Press: How Newspapers Represent Female and Male Scientists. UK Resource Centre for Women in Science, Engineering and Technology. 2008.

6. Kangourimollahajlou A. The depiction of expert women in Canadian newsapers: University of Regina; 2017.

7. von Elm E, Altman DG, Egger M, Pocock SJ, Gotzsche PC, Vandenbroucke JP, et al. The Strengthening the Reporting of Observational Studies in Epidemiology (STROBE) Statement: guidelines for reporting observational studies. Int J Surg. 2014;12(12):1495-9.

8. Solutions AP. Top 10 US Newspapers by Circulation 2020 [updated Jan 2020. Available from: https://www.agilitypr.com/resources/topmedia-outlets/top-10-daily-american-newspapers/. Accessed 20 Mar 2020

9. Census USBot. Census Regions and Divisions of the United States 2020 [Available from: https://www2.census.gov/geo/pdfs/maps-data/maps/ reference/us_regdiv.pdf. Accessed 20 Nov 2020.

10. Colleges AoAM. Active Physicians by Sex and Specialty in 2017. AAMC; 2018 December 2017. Contract No.: Table 1.3.
11. Leider JP, Plepys CM, Castrucci BC, Burke EM, Blakely CH. Trends in the Conferral of Graduate Public Health Degrees: A Triangulated Approach. Public Health Rep. 2018;133(6):729-37.

12. Wyman O. Women in healthcare leadership 2019 Oliver Wyman2019 [Available from: https://www.oliverwyman.com/our-expertise/insights/ 2019/jan/women-in-healthcare-leadership.html. Accessed 20 Nov 2020.

13. Prevention CfDCa. Past CDC Directors/Administrators CDC2020 [Available from: https://www.cdc.gov/about/history/pastdirectors. htm. Accessed 20 Nov 2020.

14. Taub A, Fisher M. If only quoting women were enough. New York Times. 2018 February 9, 2018.

15. BlackComputerHER. CiteHER Bibliography BlackComputeHER2020 [Available from: https://blackcomputeher.org/citeher-bibliography/. Accessed 15 Aug 2020.

16. Hanc $\mathbf{J}$. Campaign \#QuoteHer aims to get women's voices in healthcare reporting. Columbia Journalism Review. 2017 November 17, 2017.

17. Cheeseman Day J, Christnacht C. Women Hold 76\% of All Health Care Jobs, Gaining in Higher-Paying Occupations 2019 [Available from: https://www.census.gov/library/stories/2019/08/your-health-care-inwomens-hands.html. Accessed 20 Nov 2020.

18. Tecco H. Women in Healthcare 2017: How does our industry stack up? 2017 [Available from: https://rockhealth.com/reports/women-in-healthcare-2017-how-does-our-industry-stack-up/.

19. Perry MJ. Women earned majority of doctoral degrees in 2017 for 9th straight year and outnumber men in grad school 137 to 100: American Enterprise Institute; 2018 [Available from: https://www.aei.org/carpediem/women-earned-majority-of-doctoral-degrees-in-2017-for-9thstraight-year-and-outnumber-men-in-grad-school-137-to-100-2/. Accessed 20 Nov 2020.

20. Funk C, Parker K. Diversity in the STEM workforce varies widely across jobs. Pew Research Center; 2018.

Publisher's Note: Springer Nature remains neutral with regard to jurisdictional claims in published maps and institutional affiliations. 